\title{
Mathematical Model of Cervical Cancer Treatment Using Chemotherapy Drug
}

\author{
Murtono $^{1, *}$, Meksianis Zadrak Ndii ${ }^{2}$, Sugiyanto $^{3}$ \\ ${ }^{1}$ Department of Physics Education; ${ }^{3}$ Department of Mathematics, Universitas Islam Negeri Sunan Kalijaga, 55281, Yogyakarta, Indonesia. \\ ${ }^{2}$ Department of Mathematics, Faculty of Science and Engineering, University of Nusa Cendana, Kupang-NTT, Indonesia. \\ Author correspondency*: \\ hasnamur@yahoo.co.id
}

\begin{abstract}
Cervical cancer is a malignant disease that causes problems in women's health, especially in developing countries such as Indonesia. Cervical cancer cells will develop quickly, uncontrollably, and will continue to divide and then infiltrate the surrounding tissue and continue to spread to connective tissue, blood, and attack important organs and spinal nerves. The aim of the research is to study the mathematical model of cervical cancer by chemotherapy treatment. The results of this study are that cervical cancer treatment using chemotherapy is effective enough to kill abnormal cells such as infected cells, pre-cancerous cells and cancer cells, although there are side effects, namely the killing of normal cells due to chemotherapy drugs.
\end{abstract}

Keywords: Cervical cancer; infected cells; infected cells; cancer cells; chemotherapy

\section{INTRODUCTION}

Cervical cancer is an excessive and uncontrolled cell growth around the cervix (Walboomers et. al., 1999). Cervical cancer originated from cells in the cervix (Naganawa et al., 2005). Most cervical cancers begin in the transformation zone which is a shift from squamous cell type to cylindrical cell type. These cells do not directly turn into cervical cancer. Normal cervical cells due to the influence of carcinogenic substances can develop gradually into pre-cancerous cells and then become cancer cells (Sari et al., 2016).

The main trigger for the emergence of cervical cancer is infection of several types of high-risk Human Papilloma Virus (HPV) which causes proliferation of the epidermal surface and cervical mucosa (Bosch, 1995). The types of HPV that are very common in cases of cervical cancer are types 16 and 18 , which is more than $70 \%$ of all cervical cancers reported. The results of a study of 1,000 samples from 22 countries proved the presence of HPV infection in $99.7 \%$ of cervical cancer cases (Wuryanti et. al., 2015). Cervical cancer is the second most common type of cancer in women worldwide to breast cancer (Boice et. al., 2002).

Chemotherapy is a kind of cancer treatment that uses drugs to destroy cancer cells. Chemotherapy works by stopping or slowing the growth of cancer cells, which grow and divide rapidly. Chemotherapy can also harm healthy cells that divide rapidly, such as the lines of the mouth and intestines or cells that affect growth. Damage to healthy cells can cause side effects. Often, side effects will be disappear after chemotherapy is complete (Rose et. al., 1999). Reduction of the mass of cervical cancer can be used as used to measure the effectiveness of treatment because chemotherapy can cause shrinkage of the mass of cervical cancer. Cancer mass has an important role to detect the prognosis of a cervical cancer.

\section{FORMULATION OF MODEL}

This model developed frpm the past research (Asih, et. al., 2015) about the development of cervical cancer and Pillis et al. (2007) about the model of treating cancer in general with chemotherapy.

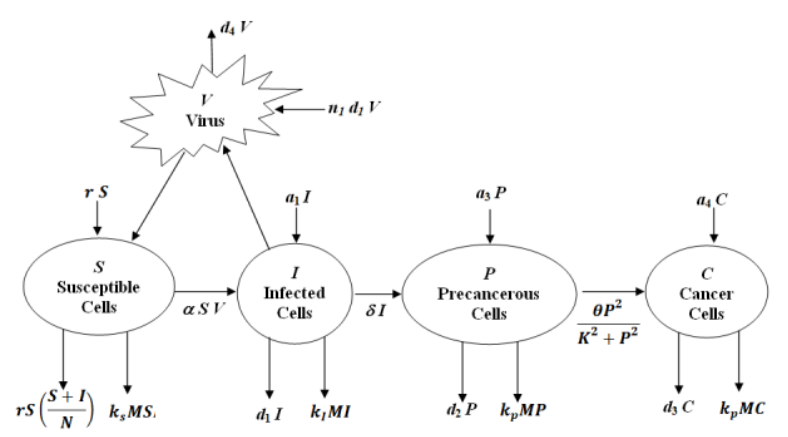

Figure 1. Cervical Cancer Treatment Diagram by Chemotherapy. 
Table 1. Subpopulations, Parameters and units.

\begin{tabular}{|c|c|c|}
\hline Symbol & Symbol Explanation Unit & Unit \\
\hline$S(t)$ & Normal cell density & cell $/ \mathrm{mm}^{2}$ \\
\hline$I(t)$ & Infected cell density & cell $/ \mathrm{mm}^{2}$ \\
\hline$P(t)$ & Pre-cancerous cell density & cell $/ \mathrm{mm}^{2}$ \\
\hline$C(t)$ & Cancer cell density & cell $/ \mathrm{mm}^{2}$ \\
\hline$V(t)$ & Virus density & virus $/ \mathrm{mm}^{2}$ \\
\hline$M(t)$ & $\begin{array}{l}\text { Concentration of chemotherapy } \\
\text { drugs }\end{array}$ & $\mathrm{mg} / \mathrm{m}^{2}$ \\
\hline$r$ & Growth rate of normal cell & 1/day \\
\hline$N$ & Homeostatic carrying capacity & cell $/ \mathrm{mm}^{3}$ \\
\hline$\alpha$ & The rate of infection & 1/(day.virus) \\
\hline$a_{1}$ & $\begin{array}{l}\text { The rate of proliferation of } \\
\text { infected cells }\end{array}$ & 1/day \\
\hline$d_{1}$ & The rate of infected cell apoptosis & 1/day \\
\hline$\delta$ & $\begin{array}{l}\text { The rate of progression, from } \\
\text { infection to pre-cancer }\end{array}$ & 1/day \\
\hline$a_{2}$ & $\begin{array}{l}\text { The rate of proliferation of pre- } \\
\text { cancerous cell }\end{array}$ & 1/day \\
\hline$d_{2}$ & $\begin{array}{l}\text { The rate of pre-cancerous cell } \\
\text { apoptosis }\end{array}$ & 1/day \\
\hline$\theta$ & $\begin{array}{l}\text { The maximum invasion rate, from } \\
\text { precancerous to cancer }\end{array}$ & 1/day \\
\hline$K$ & Half-saturation consentration & cell $/ \mathrm{mm}^{3}$ \\
\hline$a_{3}$ & Cancer cell proliferation rate & 1/day \\
\hline$d_{3}$ & $\begin{array}{l}\text { Summing the rate of apoptosis and } \\
\text { the rate of cancer cell metastasis }\end{array}$ & 1/day \\
\hline$n$ & $\begin{array}{l}\text { The average number of viruses } \\
\text { produced by an infected cell }\end{array}$ & constant \\
\hline$d_{4}$ & The rate of virus death & 1/day \\
\hline$k_{S}$ & $\begin{array}{l}\text { Fractional susceptible cells kill by } \\
\text { chemotherapy }\end{array}$ & 1/day \\
\hline$k_{I}$ & $\begin{array}{l}\text { Fractional infected cells kill by } \\
\text { chemotherapy }\end{array}$ & 1/day \\
\hline$k_{P}$ & $\begin{array}{l}\text { Fractional pre-cancerous cells kill } \\
\text { by chemotherapy }\end{array}$ & 1/day \\
\hline$k_{C}$ & $\begin{array}{l}\text { Fractional cancer cells kill by } \\
\text { chemotherapy }\end{array}$ & 1/day \\
\hline$\gamma$ & $\begin{array}{l}\text { The rate of chemotherapy drug } \\
\text { decay }\end{array}$ & 1/day \\
\hline$v_{M}$ & $\begin{array}{l}\text { The rate of chemotherapy drug } \\
\text { intake }\end{array}$ & $\mathrm{mg} / \mathrm{m}^{2}$.day \\
\hline
\end{tabular}

The dynamics of changes in cervical cells from normal cells to cancer cells are given in the following system of differential equations:

$$
\begin{aligned}
& \frac{d S}{d t}=r S\left(1-\frac{S+I}{N}\right)-\alpha S V-k_{S} M S \\
& \frac{d I}{d t}=\alpha S V+a_{1} I-d_{1} I-\delta I-k_{I} M I \\
& \frac{d V}{d t}=n_{1} d_{1} I-d_{4} V
\end{aligned}
$$

$\frac{d P}{d t}=\delta I+a_{2} P-d_{2} P-\frac{\theta P^{2}}{K^{2}+P^{2}}-k_{P} M P$

$\frac{d C}{d t}=\frac{\theta P^{2}}{K^{2}+P^{2}}+a_{3} C-d_{3} C-k_{C} M C$

$\frac{d M}{d t}=-\gamma M+v_{M}$

Let

$$
\begin{gathered}
a=d_{1}-a_{1}, b=a_{2}-d_{2}, k=d_{3}-a_{3}, S_{1}=\frac{S}{N}, I_{1}=\frac{I}{N}, \\
P_{1}=\frac{P}{K}, C_{1}=\frac{C}{K}, n=n_{1} d_{1} N, c=d_{4}, p=\frac{N}{K}, \tilde{\theta}=\frac{\theta}{K}
\end{gathered}
$$

By non-conventionalizing the System (1a) - (1f) to be

$\frac{d S}{d t}=\frac{d S_{1}}{d t}=r S_{1}\left(1-\left(S_{1}+I_{1}\right)\right)-\alpha S_{1} V-k_{S} M S_{1}$

$\frac{d I}{d t}=\frac{d I_{1}}{d t}=\alpha S V-a I-\delta I-k_{I} M I$

$\frac{d V}{d t}=n I-c V$

$\frac{d P_{1}}{d t}=\delta p I+b P-\tilde{\theta} \frac{P^{2}}{1+P^{2}}-k_{p} M P_{1}$

$\frac{d C}{d t}=\tilde{\theta} \frac{P^{2}}{1+P^{2}}-k C-k_{C} M C$

$\frac{d M}{d t}=-\gamma M+v_{M}$

By eliminating the variable index, System (2a) - (2f) which is non-professional becomes

$$
\begin{aligned}
& \frac{d S}{d t}=r S(1-(S+I))-\alpha S V-k_{S} M S \\
& \frac{d I}{d t}=\alpha S V-\alpha I-\delta I-k_{I} M I
\end{aligned}
$$

$\frac{d V}{d t}=n I-c V$

$\frac{d P}{d t}=\delta p I+b P-\frac{\theta P^{2}}{1+P^{2}}-k_{P} M P$

$\frac{d C}{d t}=\frac{\theta P^{2}}{1+P^{2}}-k C-k_{C} M C$

$\frac{d M}{d t}=-\gamma M+v_{M}$ 


\section{EQUILIBRIUM POINT}

Theorem 1. Let $u=2 x^{3}-9 x y+27 z, v=x^{2}-3 y$.

The equilibrium point with chemotherapy in cervical cancer from System (3a) - (3f) is

$$
\begin{aligned}
E P & =\left(S^{*}, I^{*}, P^{*}, C^{*}, V^{*}, M^{*}\right) \\
& =\left(\xi_{3}+\xi_{4} \xi_{5}, \xi_{5}, \xi_{2} \xi_{5}, p_{i}, c_{i}, \xi_{1}\right)
\end{aligned}
$$

$i=1,2,3$, where $\xi_{1}=\frac{v_{M}}{\gamma}>0, \xi_{2}=\frac{n}{c}>0, \xi_{3}=1-\frac{k_{S} \xi_{1}}{r}$,

$\xi_{4}=-\left(1+\frac{\alpha \xi_{2}}{r}\right)<0$,

$\xi_{5}=\frac{a+\delta+k_{I} \xi_{1}-\alpha \xi_{2} \xi_{3}}{\alpha \xi_{2} \xi_{4}}, x=\frac{\theta-\delta p \xi_{5}}{k_{P} \xi_{1}-b}$,

$y=\frac{k_{P} \xi_{1}-b}{k_{P} \xi_{1}-b}, z=-\frac{\delta p \xi_{5}}{k_{P} \xi_{1}-b}$.

\section{Proof.}

From equation (3f) is obtained

$$
M=\frac{v_{M}}{\gamma}=\xi_{1}>0 \text {. }
$$

From equation (3c) is obtained

$V=\frac{n I}{c}=\xi_{2} I$,

where $\xi_{2}=\frac{n}{c}>0$.

If equation (4) and equation (5) are substituted into equation (3a), then we obtain

$S=\xi_{3}+\xi_{4} I$,

where $\xi_{3}=1-\frac{k_{S} \xi_{1}}{r} \quad$ and $\quad \xi_{4}=-\left(1+\frac{\alpha \xi_{2}}{r}\right)$.

If equations (4), (5) and (6) are substituted in equation (3b), they are obtained

$I=0$ or $I=\frac{a+\delta+k_{I} \xi_{1}-\alpha \xi_{2} \xi_{3}}{\alpha \xi_{2} \xi_{4}}=\xi_{5}$,

where $\xi_{5}=\frac{a+\delta+k_{I} \xi_{1}-\alpha \xi_{2} \xi_{3}}{\alpha \xi_{2} \xi_{4}}$.

For $I=0$ impossible, because the virus is the cause of cervical cancer, so it was chosen $I=\xi_{5}$. If equation (4) and equation (7) are substituted into equation (1d), then they are obtained $P^{3}+x P^{2}+y P+z=0$, where

$$
x=\frac{\theta-\delta p \xi_{5}}{k_{P} \xi_{1}-b}, y=\frac{k_{P} \xi_{1}-b}{k_{P} \xi_{1}-b}, z=-\frac{\delta p \xi_{5}}{k_{P} \xi_{1}-b} .
$$

The roots are

$$
\begin{gathered}
p_{1}=-\frac{x}{3}-\frac{1}{3} \sqrt[3]{\frac{1}{2}\left[u+\sqrt{u^{2}-4 v^{3}}\right]}- \\
\frac{1}{3} \sqrt[3]{\frac{1}{2}\left[u-\sqrt{u^{2}-4 v^{3}}\right]}, \\
p_{2}=-\frac{x}{3}+\frac{1-i \sqrt{3}}{6} \sqrt[3]{\frac{1}{2}\left[u+\sqrt{u^{2}-4 v^{3}}\right]}+ \\
p_{3}=-\frac{x}{3}+\frac{1+i \sqrt{3}}{6} \sqrt[3]{\frac{1}{2}\left[u-\sqrt{u^{2}-4 v^{3}}\right]} \sqrt[3]{\frac{1}{2}\left[u+\sqrt{u^{2}-4 v^{3}}\right]}+ \\
\frac{1-i \sqrt{3}}{6} \sqrt[3]{\frac{1}{2}\left[u-\sqrt{u^{2}-4 v^{3}}\right]}
\end{gathered}
$$

If equation (4) and equation (8) are substituted into equation (3e), then they are obtained $C=$ $\frac{\theta p_{i}{ }^{2}}{\left(k+k_{C} \xi_{1}\right)\left(1+p_{i}{ }^{2}\right)}=c_{i}$, where $i=1,2,3$

Theorem 2. If $a+\delta+k_{I} \xi_{1}-\alpha \xi_{2} \xi_{3}>0, \quad \xi_{3}+\xi_{4} \xi_{5}>0$ and if one $p_{i}>0$ and real, then the equilibrium point with chemotherapy or value $E P$ exist.

\section{Proof.}

From Theorem 1 is obtained $M=\frac{v_{M}}{\gamma}=\xi_{1}>0$. Because $a+\delta+k_{I} \xi_{1}-a \xi_{2} \xi_{3}>0$, then $I=\frac{a+\delta+k_{I} \xi_{1}-a \xi_{2} \xi_{3}}{a \xi_{2} \xi_{4}}=$ $\xi_{5}>0$. Because $I=\xi_{5}>0$, then $V=\frac{n I}{c}=\xi_{2} I>0$. Because $\xi_{3}+\xi_{4} \xi_{5}>0$, then $S=\xi_{3}+\xi_{4} \xi_{5}>0$. One is $p_{i}>0$, where $i=1,2,3$ and real. Value is $\frac{\theta p_{i}{ }^{2}}{\left(k+k_{C} \xi_{1}\right)\left(1+p_{i}{ }^{2}\right)}=c_{i}>0$. So, the equilibrium point with chemotherapy or value $E P$ exist

\section{STABILITY}

Theorem 3. Let $u=2 x^{3}-9 x y+27 z, v=x^{2}-3 y$. If $-k-k_{C} \xi_{1}<0, \quad b-\frac{2 \theta p_{i}}{\left(1+p_{i}{ }^{2}\right)}-k_{P} \xi_{1}<0, \quad$ where $i=$ $1,2,3, x>0, u>0, u^{2}=4 v^{3}$, and $u<2 x^{3}$, then equilibrium point $E P=\left(\xi_{3}+\xi_{4} \xi_{5}, \xi_{5}, \xi_{2} \xi_{5}, p_{i}, c_{i}, \xi_{1}\right)$ asymptotic stable.

\section{Proof.}

From System (3a) - (3f) the Jacobian matrix with eigenvalue is obtained

$$
\lambda_{1}=-\gamma, \lambda_{2}=-k-k_{C} \xi_{1}, \lambda_{3}=b-\frac{2 \theta p_{i}}{\left(1+p_{i}^{2}\right)^{2}}-k_{P} \xi_{1},
$$




$$
\begin{array}{r}
\lambda_{4}=-\frac{x}{3}-\frac{1}{3} \sqrt[3]{\frac{1}{2}\left[u+\sqrt{u^{2}-4 v^{3}}\right]}- \\
\frac{1}{3} \sqrt[3]{\frac{1}{2}\left[u-\sqrt{u^{2}-4 v^{3}}\right]}, \\
\lambda_{5}=-\frac{x}{3}+\frac{1-i \sqrt{3}}{6} \sqrt[3]{\frac{1}{2}\left[u+\sqrt{u^{2}-4 v^{3}}\right]}+ \\
\lambda_{6}=-\frac{x}{3}+\frac{1+i \sqrt{3}}{6} \sqrt[3]{\frac{1}{2}\left[u-\sqrt{u^{2}-4 v^{3}}\right]} \\
\frac{1-i \sqrt{\frac{1}{3}}}{6} \sqrt[3]{\frac{1}{2}\left[u+\sqrt{u^{2}-4 v^{3}}\right]}+
\end{array}
$$

Value is $\lambda_{1}=-\gamma<0$. Because $-k-k_{C} \xi_{1}<0$, then $\lambda_{2}=-k-k_{C} \xi_{1}<0$. Because $b-\frac{2 \theta p_{i}}{\left(1+p_{i}\right)^{2}}-k_{P} \xi_{1}<0$, then $\lambda_{2}=b-\frac{2 \theta p_{i}}{\left(1+p_{i}^{2}\right)^{2}}-k_{P} \xi_{1}<0$. Because $v=0$, then $\lambda_{4}=-\frac{x}{3}-\frac{1}{3} \sqrt[3]{u}, \quad \lambda_{5}=-\frac{x}{3}-\frac{1}{3} \sqrt[3]{\frac{1}{2} u}, \quad \lambda_{6}=-\frac{x}{3}+$ $\frac{1}{3} \sqrt[3]{\frac{1}{2} u}$. Because $u>0$, then $\lambda_{4}<0$. Because $u<x^{3}$, then $\lambda_{5}=\lambda_{6}<0$. Because $\lambda_{1}, \lambda_{2}, \lambda_{3}, \lambda_{4}, \lambda_{5}$ and $\lambda_{6}$, then the equilibrium point $E P$ asymptotic stable.

\section{SIMULATION}

In this section we will discuss numerical simulations and medical interpretations of the mathematical model of cervical cancer affected by chemotherapy. First, the parameter values used and the initial values for each variable are given first. Taking parameter values for numerical simulations is still in the form of assumptions based on the rate of growth of cancer cells in general. Sources and interpretations of parameter values can be seen in the reference. The parameter values for this case are given in Table 2 .

Table 2. Case Parameter Value of the Effects of Chemotherapy.

\begin{tabular}{cll}
\hline Symbol & Value & Reference \\
\hline$r$ & 0.02 & Asih et al. (2015) \\
$\alpha$ & 0.0001 & Asih et al. (2015) \\
$a$ & 0.01 & Asih et al. (2015) \\
$\delta$ & 0.0082 & Asih et al. (2015) \\
$n$ & 10000 & Asih et al. (2015) \\
$c$ & 50 & Asih et al. (2015) \\
$p$ & 13.44 & Asih et al. (2015) \\
$b$ & 1 & Asih et al. (2015) \\
$\theta$ & 2.03 & Asih et al. (2015) \\
$k$ & 1.01 & Asih et al. (2015) \\
$k_{S}$ & 0.0006 & Estimation \\
$k_{I}$ & 0.6 & Pillis et al. (2007) \\
$k_{P}$ & 0.6 & Pillis et al. (2007) \\
$k_{C}$ & 0.8 & Pillis et al. (2007) \\
$\gamma$ & 0.9 & Pillis et al. (2007) \\
$v_{M}$ & 1 & Pillis et al. (2007) \\
\hline
\end{tabular}

A

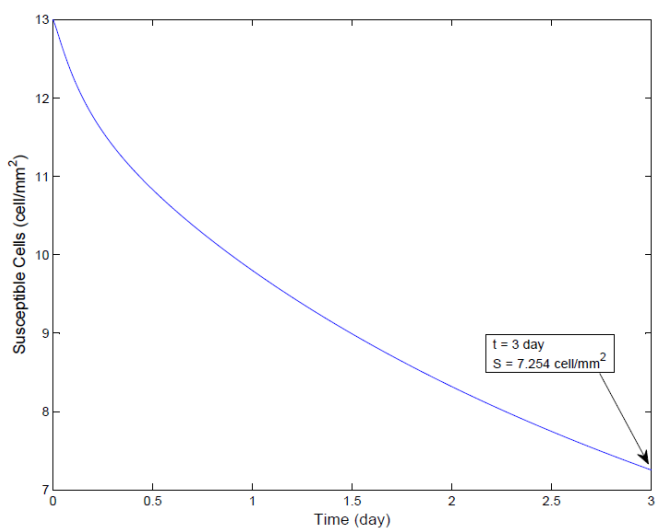

B

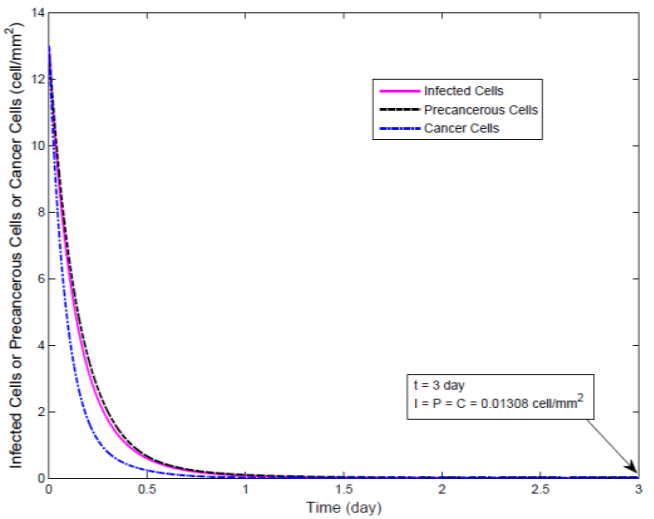

(C)

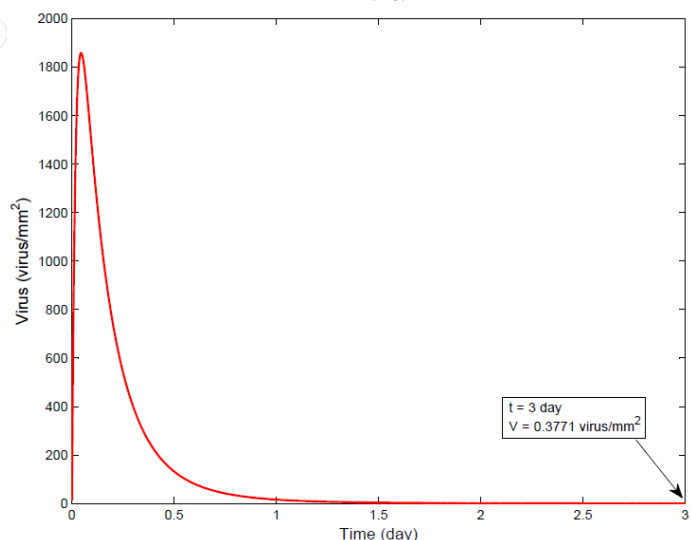

D

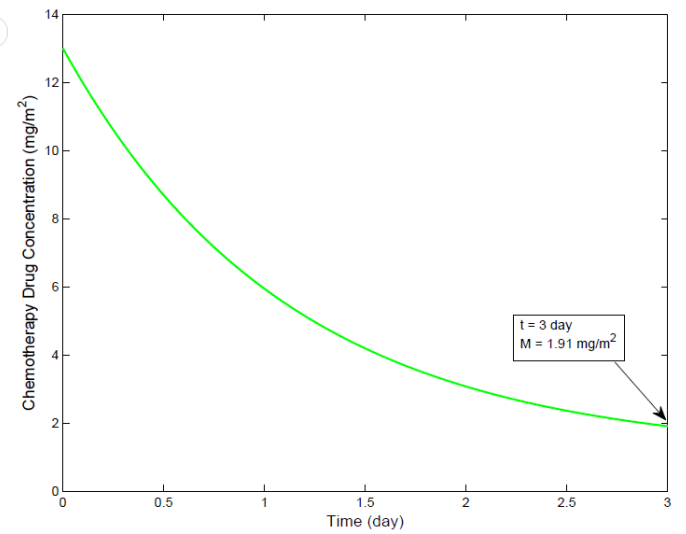

Figure 2. System Simulation (3a) - (3f) with parameter values $r=0, \alpha=$ $0.0001, a=0.01, \delta=0.0082, n=10000, c=50, p=13.44, b=1$, $\theta=2.03, k=1.01, k_{S}=0.0006, k_{I}=0.6, k_{P}=0.6, k_{C}=0.8, \gamma=$ $0.9, \gamma=1$, and initial conditions $(13,13,13,13,13,13)$. The dynamics due to normal cell chemotherapy drugs, infected cells, precancerous cells, cancer cells, cancer cells, and viruses declined in three days. (A) normal cells. (B) Infected cells, precancerous cells, and cancer cells. (C) Viruses. (D) Chemotherapy drug concentration. 
Figure 2 shows a trajectory with the influence of chemotherapy drugs, on cervical cancer patients. Normal cells in the first 3 days showed a decrease, from 13 cells $/ \mathrm{mm}^{2}$ to 7,254 cells $/ \mathrm{mm}^{2}$. This makes a severe effect for cervical cancer patients with this chemotherapy drug. Infected cells, precancerous cells and cancer cells drop very quickly, in the first 3 days of chemotherapy, from 13 cells $/ \mathrm{mm}^{2}$ to 0.01308 cells $/ \mathrm{mm}^{2}$. The initial virus rose would derease after chemotherapy. The virus in 3 days is from 13 viruses $/ \mathrm{mm}^{2}$ to 0.3771 viruses $/ \mathrm{mm}^{2}$. This is because, many infected cells die because of the effects of chemotherapy drugs. The chemotherapy drug on the third day still contained $1.91 \mathrm{mg} / \mathrm{m}^{2}$. It means that chemotherapy drugs still have an effect on normal cells and other abnormal cells, including cancer cells.

\section{CONCLUSION}

Cervical cancer is one type of malignant cancer and is most prevalent in women compared to other cancers. Treatment of cervical cancer with chemotherapy is quite effective. Abnormal cancer cells such as infected cells, precancerous cells, and many cancer cells die from this treatment. Because normal cells are dead, this is the side effect of the of this treatment. This research needs to be continued with other treatments that are more effective, especially to reduce the adverse effects to the normal cell.

\section{REFERENCES}

Asih, T. S. N., Lenhart, S., Wise, S., Aryati, L., Adi-Kusumo, F., Hardianti, M. S., \& Forde, J. (2016). The dynamics of HPV infection and cervical cancer cells. Bulletin of mathematical biology, 78(1), 4-20.
Boice Jr, J. D., Day, N. E., Andersen, A., Brinton, L. A., Brown, R., Choi, N. W., ... \& Hakama, M. (1985). Second cancers following radiation treatment for cervical cancer. An international collaboration among cancer registries. Journal of the National Cancer Institute, 74(5), 955-975.

Bosch, F. X., Manos, M. M., Muñoz, N., Sherman, M., Jansen, A. M., Peto, J., ... \& Shan, K. V. (1995). Prevalence of human papillomavirus in cervical cancer: a worldwide perspective. JNCI: Journal of the National Cancer Institute, 87(11), 796-802.

de Pillis, L. G., Gu, W., Fister, K. R., Head, T. A., Maples, K., Murugan, A., ... \& Yoshida, K. (2007). Chemotherapy for tumors: An analysis of the dynamics and a study of quadratic and linear optimal controls. Mathematical Biosciences, 209(1), 292-315.

Naganawa, S., Sato, C., Kumada, H., Ishigaki, T., Miura, S., \& Takizawa, O. (2005). Apparent diffusion coefficient in cervical cancer of the uterus: comparison with the normal uterine cervix. European radiology, 15(1), 71-78.

Rose, P. G., Bundy, B. N., Watkins, E. B., Thigpen, J. T., Deppe, G., Maiman, M. A., ... \& Insalaco, S. (1999). Concurrent cisplatin-based radiotherapy and chemotherapy for locally advanced cervical cancer. New England Journal of Medicine, 340(15), 1144-1153.

Sari, H. E., Mudigdo, A., \& Demartoto, A. (2016). Multilevel Analysis on the Social Determinants of Cervical Cancer in Yogyakarta. Journal of Epidemiology and Public Health, 1(2), 100-107.

Walboomers, J. M., Jacobs, M. V., Manos, M. M., Bosch, F. X., Kummer, J. A., Shah, K. V., ... \& Muñoz, N. (1999). Human papillomavirus is a necessary cause of invasive cervical cancer worldwide. The Journal of pathology, 189(1), 12-19.

Wuryanti, S., Andrijono, A., Susworo, S., \& Witjaksono, F. (2015). The effect of high poly unsaturated fatty acid (PUFA) dietary supplementation on inflammatory status of patients with advanced cervical cancer on radiation treatment. Acta Medica Indonesiana, 47(1). 
THIS PAGE INTENTIONALLY LEFT BLANK 